\title{
Crianças E adolescentes NA AGENdA POLÍTICA DA SAÚDE MENTAL BRASILEIRA: INCLUSÃO TARDIA, DESAFIOS ATUAIS
}

\author{
MENTAL HEALTH OF CHILDREN AND ADOLESCENTS IN THE BRAZILIAN \\ PUBLIC HEALTH AGENDA: LATE ONSET AND CURRENT CHALLENGES
}

SALUD MENTAL DE NIÑOS Y ADOLESCENTES EN LA AGENDA DE SALUD PÚBLICA EN BRASIL: INICIO TARDÍO Y RETOS ACTUALES

Maria Cristina Ventura Couto* Pedro Gabriel Godinho Delgado**

\section{Resumo}

Com base no argumento de que até o final do século XX não era possível afirmar a existência, no contexto brasileiro, de uma política de saúde mental para crianças e adolescentes (SMCA), o artigo analisa os possíveis determinantes da inclusão tardia deste tema na agenda política da saúde mental brasileira. Como parte desta análise, identifica e descreve as duas ações prioritárias escolhidas pelo Sistema Único de Saúde (SUS), no começo do século XXI, para iniciar o processo de construção de redes de cuidado para SMCA: a implantaçấo de Centros de Atenção Psicossocial Infantil e Juvenil (CAPSi) e o desenvolvimento de estratégias para articulaçáo intersetorial da saúde mental com setores historicamente envolvidos na assistência à infância e adolescência, como educação, assistência social, justiça/direitos. A criação dos CAPSi e o direcionamento intersetorial são aqui consideradas ações-chave para alavancar a montagem de uma rede pública ampliada de atençáo em SMCA, de base territorial, capaz de acolher as diferentes ordens de problemas envolvidos na SMCA e ampliar o acesso ao cuidado.

Palavras-chave: criança e adolescente; saúde mental; CAPSi; intersetorialidade; agenda pública.

\footnotetext{
* Universidade Federal do Rio de Janeiro, Rio de Janeiro, RJ, Brasil.

** Universidade Federal do Rio de Janeiro, Rio de Janeiro, RJ, Brasil.
} 


\section{Abstract}

Based on the argument that until the late twentieth century it was not possible to recognize, in the Brazilian context, the existence of a nationwide mental health policy for children and adolescents (MHCA), this paper analyses the historical determinants of the late onset of mental health initiatives for children and adolescents in the public health agenda in Brazil. In this regard, two priorities of the National Health System (SUS), both established from the beginning of 2000's, are identified and discussed: the implementation of Community Psychosocial Care Centers (known by the Portuguese acronym CAPSi) and the development of collaborative care within the health sector and through multiagency collaboration, especially involving educational, forensic/advocacy and social assistance sectors. The CAPSi implementation and the multiagency collaboration are the main actions to achieve the establishment of a public mental health care network for children and adolescents, community-based, able to receive the multiplicity of MHCA problems and to assure the access to mental health services.

Keywords: child and adolescent; mental health; community mental health services; multiagency collaboration; public agenda.

\section{RESUMEN}

Basado en el argumento de que hasta finales del siglo XX no era posible reconocer, en el contexto brasileño, una política de salud mental para niños y adolescentes (SMNA), este artículo analizar los determinantes para el retraso de inserción de la salud mental de niños y adolescentes (SMNA) en la agenda de la salud pública en Brasil, además de identificar y describirlas dos acciones prioritarias elegidas por el Sistema Único de Salud (SUS), a inicios del siglo XXI, para empezar la construcción de redes de atención en SMNA: la implantación de los Centros de Atención Psicosocial para Niños y Adolescentes (CAPSi) y el desarrollo de estrategias de cooperación intersectores entre la salud mental y educación, asistencia social, justicia, sectores históricamente involucrados en la atención de niños y jóvenes. La creación de CAPSi y la cooperación intersectores se consideran las principales acciones para la introducción de una red pública ampliada en SMNA, con ubicación en el territorio, capaz de adaptarse a los diferentes órdenes de problemas relacionados con la SMNA y de ampliar el acceso a la atención.

Palabras clave: niños y adolescentes; salud mental; centros de atención psicosocial para niños y adolescentes; agenda pública; cooperación intersectorial. 
Os caminhos para o desenvolvimento de uma Política de Saúde Mental para Crianças e Adolescentes (SMCA) no Brasil só foram propostos no início do século XXI. Antes desse momento, o país não dispunha de formulaçóes pelo setor da saúde mental que orientassem a construção de uma rede de cuidados para crianças e adolescentes com problemas mentais, ficando as açóes assistenciais, quando existentes, circunscritas à agenda dos setores da assistência social e educação, com propostas mais reparadoras e disciplinares do que propriamente clínicas ou psicossociais. A política atual de SMCA, voltada para a construção de redes ampliadas e intersetoriais de atenção, de base comunitária, com ênfase na articulação entre serviços de diferentes níveis de complexidades e tendo como ações estratégicas iniciais a oferta de Centros de Atenção Psicossocial Infantis e Juvenis (CAPSi) e a articulação intersetorial (Couto, Duarte \& Delgado, 2008), visa à superação do cenário anterior, no qual, a rigor, crianças e adolescentes com necessidades em saúde mental ficaram desassistidas ou submetidas a processos de institucionalização externos ao sistema psiquiátrico asilar, que, por décadas, foram invisíveis até mesmo ao vigoroso movimento da Reforma Psiquiátrica brasileira (Couto, 2004).

A análise do enfrentamento tardio pela saúde mental das questóes relacionadas às crianças e adolescentes com problemas mentais poderá auxiliar no entendimento de quais os reais pontos de superação e os principais desafios que a rede atual de atenção psicossocial tem a desenvolver e realizar nos territórios para que sejam escritas novas linhas na história brasileira de cuidado à infância e adolescência.

Neste artigo serão analisados possíveis determinantes para a inclusão tardia da SMCA na agenda pública da saúde mental, assim como apresentadas as duas ações escolhidas pelo Sistema Único de Saúde (SUS) para alavancar o processo de implantação das redes ampliadas de cuidado: os CAPSi e as estratégias para articulação intersetorial da saúde mental com setores historicamente envolvidos na assistência à infância e adolescência, como educação, assistência social, justiça e direitos.

\section{Contexto de surgimento da Política de Saúde Mental para Crianças e Adolescentes}

As políticas públicas no Brasil nos últimos 20 anos são tributárias da ampla redefinição das funçóes do Estado e de seu compromisso com a equidade e o bem-estar social construídos no período da redemocratização do país e expressos 
na Constituição Federal de 1988. Em relação à infância e adolescência, essas políticas estão também amparadas no movimento internacional de defesa de direitos, que gerou uma profunda mudança nas concepçóes sobre a criança e o adolescente, instando as sociedades a reconstruir suas agendas e açóes dirigidas a eles. $\mathrm{Na}$ área da saúde, a síntese do esforço de redesenhar o dever do Estado brasileiro na garantia do acesso à saúde expressou-se na proposição do Sistema Único de Saúde, o SUS, de 1990, proposta generosa de uma política pública baseada no princípio da equidade e da universalidade do acesso.

$\mathrm{Na}$ conjuntura de renovação das funçóes do Estado, possibilitada pelo amplo movimento de redemocratização durante os anos 80 do século passado, foram inscritas algumas das condiçōes de possibilidade para que os problemas de saúde mental de crianças e adolescentes passassem a integrar, no início do século XXI, a agenda da saúde mental pública sob uma perspectiva diametralmente oposta às linhas de assistência seguidas por quase 80 anos da República brasileira. Em relação à criança e ao adolescente, o Estado brasileiro teve, historicamente, duas conformaçóes distintas: uma mais tutelar, disciplinar e amparada na institucionalização, que orientou as primeiras oito décadas da República; e outra, radicalmente diversa, baseada no princípio da proteção, na premissa da criança e do adolescente como sujeitos de direitos e amparada na proposta do cuidado em liberdade. $\mathrm{O}$ momento histórico de mudança dessas duas conformaçóes ocorreu com a redemocratização, a Constituição de 1988 e as conquistas sociais dos anos 80 e 90 do século passado.

A hipótese que orienta este trabalho é a de que houve uma inserção tardia da saúde mental infantil e juvenil na agenda da saúde pública brasileira e no processo conhecido como Reforma Psiquiátrica. As ações que contribuíram para a construção dessa nova agenda desenvolveram-se apenas a partir de 2001, quando as condiçóes concretas de possibilidade para a SMCA como política pública se tornaram visíveis e eficazes. Argumentaremos que essas condições advieram de acontecimentos diretamente ligados ao campo da saúde mental, os quais ampliaram substancialmente sua institucionalidade; e de outros, externos a ele, que inscreveram uma nova concepção de criança e adolescente no ordenamento jurídico, político e social brasileiro, com consequências para a qualificação das ações públicas dirigidas ao seu cuidado e proteção.

A promulgação da Lei da Saúde Mental, Lei 10.216 (Brasil, 2001a) e a realização da III Conferência Nacional de Saúde Mental (CNSM), ambas ocorridas em 2001, elevaram o patamar de institucionalidade da Reforma Psiquiátrica brasileira, ampliando o alcance de suas açôes e o horizonte de aplicação de seus princípios. Com essa Lei, a saúde mental passou a constituir-se como uma políti- 
ca de Estado ancorada na defesa dos direitos de cidadania dos pacientes mentais e náo apenas como um programa de governo. Com a III CNSM, o campo da saúde mental viu ratificado o anseio social pela substituição no país do modelo de tratamento baseado na centralidade do hospital pelo modelo comunitário de atenção. A inflexão comunitária fez emergirem novas questôes para a saúde mental - só visíveis a partir do território - como a necessidade de inclusão no campo do cuidado psicossocial dos problemas mentais em crianças e adolescentes que, por décadas, foram desconsiderados na agenda pública ou ficaram relegados à intervenção de instituiçôes de caráter disciplinar, corretivo ou normalizador, situadas fora do sistema formal de saúde mental (Couto, 2004).

Externamente à saúde mental, dois eventos se inscreveram na história como marcos na construção social e política de uma nova concepção de criança e adolescente. O primeiro, a Convenção Internacional sobre os Direitos da Criança, realizada pela Organização das Naçōes Unidas (ONU) em 1989, da qual o Brasil foi signatário e que sintetizou um novo paradigma para interpretar a situação da infância na sociedade ao afirmar a criança como sujeito e cidadão de plenos direitos (ONU, 1989). O segundo, a promulgação, no Brasil, do Estatuto da Criança e do Adolescente (ECA), em 1990, que estabeleceu direitos de cidadania para crianças e adolescentes e alterou a condição jurídica anterior de "menores" para a de sujeitos de direitos, substituindo a doutrina da situação irregular pela da proteçâo integral como marco orientador das novas políticas e açôes a serem dirigidas à infância e adolescência.

Esses acontecimentos - isto é, a Convenção da ONU e o ECA, no início dos anos 90, associados à emergência da Lei da saúde mental e à realização da III CNSM, em 2001 -, engendrados por movimentos sociais distintos e separados por quase uma década, foram responsáveis pela emergência de condiçôes simbólicas e reais para a proposição da política de saúde mental para crianças e adolescentes no início do século XXI. Se marcos legais por si não alteram a realidade, podem, em certas circunstâncias, produzir modulações no real, agindo ativamente na inscrição social de novas concepçôes e práticas eticamente sustentáveis.

A nova concepção de criança e adolescente, possibilitada pelo marco dos direitos humanos, permitiu que fossem reconhecidos como questôes relevantes para as políticas públicas de cuidado aspectos fundamentais de sua condição de sujeito psíquico: além de seres vivos e sociais, crianças e adolescentes são seres falantes (Cirino, 2001), agentes de sua subjetivação frente às experiências no mundo (Ferreira, 1999). Guardam em comum com todos que partilham a condiçáo humana o fato de terem histórias de vida e experiências particulares, serem atravessados pelos enigmas da existência, sofrerem, transtornarem-se e poderem 
expressar de diferentes maneiras seu transtorno, mal-estar ou sofrimento intenso. São sujeitos plenos, portanto, que podem se desenvolver, socializar, aprender, mas também serem atravessados por enigmas e vicissitudes subjetivas, inerentes à sua condição humana. São seres passíveis de sofrimento e adoecimento mental, com direito de serem cuidados quando o sofrimento se fizer insuportável ou quando impossibilitar a construção ou sustentação de laços sociais sem que esse cuidado se reduza à correção, normalização ou adaptação de comportamentos.

Essa nova noção de criança e adolescente foi destacada na III Conferência Nacional de Saúde Mental (Brasil, 2002a). Realizada em dezembro de 2001, essa Conferência constitui um divisor de águas na história da saúde mental de crianças e adolescentes no país, porque, de modo inédito em relação às duas conferências anteriores, priorizou o tema da SMCA e convocou o Estado brasileiro à tomada de responsabilidade pelo cuidado e tratamento de crianças e adolescentes com problemas mentais, afirmando a necessidade de esse cuidado ser pautado no reconhecimento delas como sujeitos psíquicos e de direitos, ser exercido em dispositivos de base comunitária, calcado na lógica do território e da operação em rede, e ter a inclusão social possível a cada um como o norte ético da ação de cuidado.

$\mathrm{O}$ presente estudo parte do argumento de que, até o final do século XX, não era possível afirmar a existência, no contexto brasileiro, de uma política de saúde mental para crianças e adolescentes, se considerada a moldura ética e clínica delineada acima. Os caminhos para construção dessa política só foram propostos a partir de 2001 e foram fortemente dependentes dos dois movimentos anteriormente referidos - da saúde mental e dos direitos humanos - movimentos distintos, mas integralmente relacionados, que alteraram os rumos da política para a infância e a adolescência e os caminhos da saúde mental brasileira. Uma análise retrospectiva permite dizer que esses acontecimentos, por sinergia, constituíram uma ação política, no sentido atribuído à ideia de ação por Hannah Arendt (2002, p. 51), ou seja, como algo que inicia um novo começo. Nas palavras da autora: "a grande importância que o conceito de começo e origem tem para todas as questôes estritamente políticas advém do simples fato de que a ação política, como toda ação, é sempre essencialmente o começo de algo novo”.

\section{Assistência à infância e adolescência com problemas mentais nos primeiros tempos da República: breve percurso genealógico}

A afirmação de que até o final do século XX não havia, no Brasil, ações organizadas de cuidado em SMCA como respostas de políticas públicas especí- 
ficas não deve confundir ou obscurecer o fato de que a ausência dessas políticas não constituiu impedimento para que uma série de intervençóes de cunho assistencial, sob a chancela do poder público, incidisse sobre crianças e adolescentes com problemas mentais. Essas intervenções foram resultado, entretanto, de uma agenda política edificada não para cuidar do padecimento mental na infância e adolescência, mas para responder aos problemas da pobreza e do abandono, que eram considerados produtores de efeitos incapacitantes. A noção de incapacitação pela pobreza engendrou a montagem de políticas de assistência reparadoras e o desenvolvimento de práticas disciplinares e corretivas que supunham poder recuperar as mazelas da infância e adolescência pobres, compensar os danos e redirecionar os rumos para o desenvolvimento de cidadáos civilizados e produtivos.

Essa questão será aprofundada adiante. $\mathrm{O}$ argumento terá como base a formulação de Rua (1998) sobre a construção de agendas no campo das políticas públicas. Para a autora, as políticas públicas dizem respeito a um conjunto de decisôes e ações destinadas à resolução de problemas políticos que envolvem diferentes atividades, procedimentos, "expressam relações de poder e se destinam à resoluçáo pacífica de conflitos quanto a bens públicos" (Rua, 1998, p. 731) entendidos como bens que não podem ser providos e assegurados privadamente. Políticas são consideradas, portanto, resposta a alguma demanda formulada por atores sociais ou políticos que alcança status de política pública quando incluída na agenda pública. Participação social, formação de agenda, destinação financeira, proposição de modelos assistenciais e política pública são, dessa forma, termos correlacionados e interdependentes.

Ao analisar as ações públicas destinadas à juventude brasileira, Rua (1998) propóe uma distinção descritiva que pode auxiliar nosso argumento de que houve uma inclusão tardia da SMCA na agenda política da saúde mental brasileira. Para a autora, um "problema político" se distingue de um "estado de coisas", que se refere àquilo que ainda não alcançou o plano da política. Segundo Rua (1998), somente quando mobilizam grandes ou pequenos grupos, além de atores sociais estrategicamente situados, e passam a figurar como itens prioritários na agenda governamental os problemas podem ser considerados políticos. Enquanto essa inclusão na agenda pública não se dá,

o que se tem são "estados de coisas": situaçóes mais ou menos prolongadas de incômodo, injustiça, insatisfação ou perigo, que atingem grupos mais ou menos amplos da sociedade sem, todavia, chegar a compor a agenda governamental ou mobilizar as autoridades políticas (Rua, 1998, p. 732, grifo nosso). 
Com base nessa distinção, podemos dizer que os problemas mentais em crianças e adolescentes foram, na agenda pública da República nascente, temas periféricos, estados de coisas, reservados, quando muito, à ação dos especialistas. $\mathrm{O}$ verdadeiro problema político ligado à infância e adolescência, prioridade na agenda pública, foi a pobreza - traduzida ora como pobreza material, ora como pobreza moral - que, em síntese, representava a principal ameaça aos ideais republicanos de construir uma nação de homens saudáveis e produtivos (Rizzini, 1997; Priore, 1995; Arantes, 1995). Símbolo de esperança ou sinal de ameaça, a infância foi o alvo privilegiado dos investimentos públicos republicanos pela expectativa de que representaria o alcance do projeto civilizatório brasileiro, caso respondesse adequadamente aos investimentos que lhe eram dirigidos. Nesse contexto, as questôes do sofrimento mental ficaram encobertas por uma agenda construída para superar os danos da pobreza e abandono voltada à formação de cidadãos socialmente adequados e economicamente produtivos.

\section{O Estado Republicano e os problemas políticos da infância}

Com base nos estudos de Rizzini (1997), Priore (1995) e Arantes (1995) sobre as políticas de assistência à infância e adolescência, pode-se considerar que nos primeiros anos da República foi formada uma matriz de leitura, que durou ao menos 80 anos, sobre os problemas da criança, assim como sobre quais respostas seriam devidas ao Estado para responder a eles. Essa matriz foi composta por quatro elementos estruturantes: uma representaçâo social da criança, a de um menor; um marco jurídico específico, a doutrina da situação irregular, uma concepção de Estado, um ente com funçáo tutelar e de controle; e uma proposta de intervenção, a institucionalização em "reformatórios" ou "educandários", nomeação por si mesma esclarecedora das finalidades das açóes do Estado. A dinâmica entre esses elementos e as diferentes modulaçóes e inflexóes que adquiriram em determinados períodos da história constituíram a relação entre Estado, sociedade, criança e família por quase oito décadas da República brasileira, dirigindo o rumo das ações, o curso dos investimentos, a pauta política e estabelecendo direção, prioridades e objetivos da agenda pública ${ }^{1}$.

Uma fratura produzida na categoria de infância, legitimada pela doutrina da situação irregular (Mendes, 1998), definiu aqueles que seriam objeto da intervenção tutelar-corretiva do Estado e os que ficariam salvaguardados dela. A rigor, apenas o menor, filho da pobreza, foi tomado como problema de Estado. A criança, por estar sob a atenção da família e da escola, foi considerada ao abrigo dos riscos, cumprindo o processo de preparação para um dia produzir e dirigir a 
sociedade. O menor foi o verdadeiro "problema político", objeto do controle especial e considerado dependente da tutela do Estado para o pleno desenvolvimento e adaptação social.

A pobreza foi tomada, ainda, como solo de demarcação de dois personagens que constituíram o ponto de mira das estratégias assistenciais e a prioridade das pautas governamentais: o "menor em perigo", filho da pobreza, material ou afetivamente abandonado; e o "menor perigoso", cruel e potencialmente delinquente, resultado da pobreza moral (Rizzini, 1997). Eles foram identificados como um "problema social gravíssimo" (Rizzini, 1997, p. 29), a requerer respostas urgentes e eficazes do poder republicano. As açóes assistenciais e as instituiçóes organizadas para fazer frente ao problema visavam basicamente à prevenção (vigiar o menor), educação (moldar o menor), recuperação (reabilitar o menor vicioso) e repressão (conter o menor delinquente), traduzidas como as principais diretrizes do governo das crianças (Rizzini, 1997). Delineado o problema político, a agenda pública foi formulada para desenvolver assistência de natureza mais pedagógico-corretiva do que clínica ou psicossocial. Fora desse universo de problemas, as demais questóes que concerniam às crianças e adolescentes constituíram temas periféricos nas agendas públicas. Em alguns casos, foram tomadas como questóes restritas à esfera dos saberes e instituiçóes especializadas, como no "caso dos anormais de inteligência, dos menores atingidos por anomalias físico-psíquicas” (Rizzini, 1993, p. 68) ou dos muitos considerados deficientes - categoria que, a rigor, teve mais valor social do que nosográfico e determinou a institucionalização de um enorme contingente de crianças e adolescentes em abrigos especiais.

A construção de um complexo aparato médico-jurídico avalizou essa leitura dos problemas, legitimou a direção da assistência às crianças, fundamentou juridicamente as açôes tutelares do Estado e os meios escolhidos para desenvolvê-las (Rizzini, 1997; Pilotti, 1995). Pelo lado da medicina, o aporte específico veio do movimento da higiene mental, que tinha na prevenção e no método educativo os pilares de suas açôes. Embora com atuação mais diretamente voltada para as famílias, comunidades e escolas, a medicina higienista dirigida para a infância acabou por validar as propostas de intervenção calcadas no isolamento e na institucionalização, principalmente para os casos onde a prevenção não alcançava êxito, restando como solução o encaminhamento e a permanência dessas crianças em instituições fechadas, especiais, ou de reeducação (Rizzini, 1997; Arantes, 1995; Pilotti, 1995). O ideário dessa medicina foi expresso exemplarmente pelo trabalho da Liga Brasileira de Higiene Mental (LBHM) que, apoiada na noção de eugenia, "dilatou as fronteiras da psiquiatria e abrangeu o terreno social" (Costa, 1976, p. 33), tendo a infância como objeto privilegiado de intervenção. A abor- 
dagem desenvolvida pela LBHM constituiu, segundo Schechtman (1981, p. 02), "uma das primeiras iniciativas em psiquiatria infantil no Brasil", em estreita sintonia com a concepção de Estado como um ente tutelar, com função de controle e normalização de condutas.

Pelo lado da justiça, o aporte veio da doutrina da "situação irregular" - base do ordenamento jurídico especial que instituiu o Código de Menores, em 1927, conhecido como Código Melo Mattos - que forneceu o amparo legal necessário à construção da categoria social do "menor" e à montagem de modalidades institucionais específicas para recuperá-lo. A condição de menor definiu uma legião de crianças e adolescentes que foram retirados da tutela familiar, colocados sob a tutela do Estado e inseridos em instituições de recolhimento e internaçáo (internatos, asilos, educandários, reformatórios). O princípio-base era o de que a separação de crianças em risco do seu meio familiar prejudicial poderia oferecer melhores condiçôes para a formação moral, intelectual e física, garantindo sua capacidade produtiva e sua integração futura à sociedade como cidadãos bem formados.

A convergência desses dois discursos - o jurídico e o médico - deu a tônica e fundamentou as políticas assistenciais nos primeiros tempos da República, influenciando decisivamente as açóes do poder público dirigidas a crianças e a adolescentes.

Praticamente por oito décadas, os elementos da matriz de leitura constitutiva do problema político da infância permaneceram inalterados, assim como os pontos principais da agenda pública relacionada a eles. Nesse contexto, os problemas de saúde mental em crianças e adolescentes orbitaram como pautas periféricas na agenda pública, tendo sido frequentemente considerados efeitos extremos da pobreza e do abandono, e tomados como tema de interesse para os especialistas da Psiquiatria. Um ponto a destacar é o fato de que, ao mesmo tempo em que o problema do atraso ou da deficiência (no sentido mais social que nosográfico, como já referido), era avaliado como produto do contexto pobre e precário, a solução era baseada na natureza individual do problema, priorizando a internação da criança como resposta.

A institucionalização de crianças no Brasil foi realizada através de instituiçóes do campo da assistência social e filantropia, fora do sistema tradicional psiquiátrico, basicamente em educandários, reformatórios e outras instituições equivalentes. A designação dos processos de exclusão, tanto dos "menores" quanto dos "loucos", através do uso de um mesmo mecanismo, o de institucionalização, constitui, muitas vezes, um empecilho para que as especificidades de cada situação possam ser analisadas e as consequências danosas efetivamente superadas. 
Consideramos que nos dois processos ocorreu a incidência de uma mesma lógica, a da exclusão e segregação como condiçóes paradoxais para o exercício da função tutelar do Estado. Entretanto, os caminhos institucionais foram distintos e necessitam ser destacados nas análises para que os danos que produziram possam ser mais claramente compreendidos e definitivamente superados. Segundo Mendes (1998, p. 88), a não distinção entre abandonados, delinquentes e deficientes foi a "pedra angular do magma jurídico" da doutrina da situação irregular. "A essência desta doutrina se resume na criação de um marco jurídico que [legitima] uma intervenção estatal discricional sobre esta espécie de produto residual da categoria de infância, constituída pelo mundo dos menores" (Mendes, p. 88, grifo do autor).

Em grande parte dos estudos brasileiros sobre o fenômeno do abrigamento da infância pobre e desvalida, que materializou a ação de institucionalização de crianças no país, o componente da deficiência, relevante em termos de prevalência da população abrigada, frequentemente não é distinguido do simples abandono, o mesmo valendo para os transtornos mentais (Rizzini \& Rizzini, 2004). Esta indistinção, por décadas mantida invisível, apenas recentemente passou a ser objeto de análise em estudos sobre o processo de institucionalização de crianças no Brasil (Almeida \& Delgado, 2000; Rizzini, 2010) por ser considerada um dos fatores implicados no confinamento perene a que ficaram submetidas inúmeras crianças e adolescentes (Rizzini, 2010). Uma das principais pesquisadoras do tema registrou em 2010:

Hoje compreendo que nas instituiçóes algumas crianças portadoras de deficiência eram percebidas de forma difusa, ficavam confundidas entre as demais, genericamente percebidas como vítimas de "carência afetiva". [...] Náo se cogitava sequer questionar este procedimento. O que sei agora e desconhecia na época é que elas estavam condenadas ao confinamento perene. Dotadas de uma expressividade náo compreendida - ou mesmo percebida - elas eram encaminhadas para o silêncio e para o esquecimento (Rizzini, 2010, p. 7).

Mas onde situar, na construção da agenda política para a infância, as ações mais diretamente ligadas à psiquiatria infantil? Como apontado anteriormente, $\mathrm{o}$ trabalho da Liga Brasileira de Higiene Mental (LBHM), entre as décadas de 20 e 40 do século passado, foi uma das primeiras iniciativas da psiquiatria infantil no país (Schechtman, 1981) e constituiu um projeto solidário e articulado ao Estado tutelar no controle das condutas consideradas desviantes em crianças e adolescen- 
tes. Antes da LBHM, o Pavilhão Bourneville, de 1904, criado nas dependências do Hospício Nacional de Alienados, na era Juliano Moreira (Lobo, 1997; Müller, 1998; Silva, 2008; Engel, 1995), e depois o Hospital de Neuropsiquiatria Infantil, inaugurado em 1942 por Getúlio Vargas, no Engenho de Dentro (RJ) - apenas para citar alguns exemplos - foram marcos na história da psiquiatria dirigida às crianças. Entretanto, embora sejam importantes na história interna da psiquiatria infantil brasileira, foram pouco relevantes para a formulação da agenda pública da infância, marcando uma nítida e radical diferença em relação às instituiçóes psiquiátricas para os adultos, cuja relevância como componente estrutural da política pública vigente até a Reforma Psiquiátrica é inquestionável.

Para a infância e adolescência, a Reforma Psiquiátrica brasileira não significa a superação do modelo hospitalar psiquiátrico que, a rigor, não foi aplicado a elas. Significa, ao contrário, a superação da desassistência e da ausência de modelos ou projetos de cuidado que amparassem açóes cidadãs e não segregadoras. Configura-se para a Reforma, portanto, um percurso distinto dos adultos, mesmo que equivalente no que diz respeito à necessária inscrição de princípios e diretrizes potentes para orientar a montagem de redes de atenção baseadas no cuidado em liberdade.

A relevância de destacar a questão da infância e adolescência como parte da questão social na República e as formulações políticas derivadas dela está em elucidar como as pautas governamentais se concentraram em diferentes períodos da história apenas na ação de controle de determinado tipo de criança e adolescente. A restrição do foco político na pobreza foi amparada na doutrina menorista e contribuiu para deixar na sombra outras necessidades de crianças e adolescentes, que só poderiam ser reconhecidas a partir da inscrição de nova viga de sustentação jurídica, de nova definição de seus lugares, funçóes sociais e direitos, e de uma nova concepção de Estado.

Apenas nos anos 80 do século XX seriam substituídos todos os elementos constitutivos da matriz de leitura dos problemas da criança e adolescente, alterando radicalmente a posição a ser tomada pelo Estado frente a elas. A nova matriz de leitura, produto da efervescência democrática na transformação dos fundamentos do Estado brasileiro, foi baseada na alteração de todos os componentes da matriz inicial. Nela, a criança e o adolescente passam a ser sujeitos de direito; a doutrina jurídica, a da proteção integral; a concepção do Estado, a de um ente com função de proteção e bem-estar social; a proposta de intervenção, o cuidado em liberdade, de orientaçâo psicossocial.

A doutrina da proteção integral, mesmo sendo fenômeno ainda recente e não consolidado, e a Constituição democrática de 1988 moveram a estrutura 
de base onde se assentavam os projetos sociais, inscrevendo a noção de um novo Estado, com novas funçóes, como elemento constitutivo de uma nova matriz de leitura. A década de 80 é considerada, para muitos estudiosos do campo das políticas de atendimento à infância e adolescência no Brasil, um período de mudanças táo profundas que poderia ser afirmado como o período em que houve uma verdadeira "mutação social" (Vogel, 1995, p. 316).

Nessa nova moldura ético-política foram criadas condições de possibilidade para que a SMCA, sob o marco da atençáo psicossocial, encontrasse novo lugar nas agendas das políticas públicas para crianças e adolescentes. Os efeitos desses novos tempos na agenda da saúde mental só se fizeram presentes no início do século XXI - período em que efetivamente se pode afirmar no país o início de um conjunto de açóes e proposiçóes ligadas à formulação da política de saúde mental dirigida às crianças e adolescentes em acordo com os princípios éticos da Reforma Psiquiátrica e do ECA.

\section{Novos rumos para a saúde mental de crianças e adolescentes: o ponto de corte em 2001}

No ano de 2001 foi promulgada a Lei 10.216 e realizada a III Conferência Nacional de Saúde Mental (CNSM), que inaugurou um novo tempo para a SMCA pela possibilidade de serem construídas as bases éticas, políticas e clínicas para seu desenvolvimento como política pública. Com a finalidade de destacar as mudanças ocorridas com a III CNSM, e a partir dela, faremos um breve percurso pelas Conferências Nacionais de Saúde Mental, destacando nelas o debate sobre a infância e adolescência.

\section{As Conferências Nacionais de Saúde Mentale o tema da Infância e Adolescência}

A primeira CNSM foi realizada em 1987, em um momento de efervescência nacional, produzido pela abertura política e pelo vigor da campanha por uma constituição democrática. $\mathrm{Na}$ saúde mental, a expansão, em escala de dezenas de milhares de leitos, do parque manicomial durante a ditadura militar, as inúmeras denúncias de maus-tratos e abusos ocorridos nesses estabelecimentos, aliadas à perspectiva de mudança nas políticas sociais, fizeram com que a I CNSM fosse pautada por temas ligados à relação sociedade-estado, com críticas à instituição psiquiátrica como instrumento de dominação e exclusão. O Relatório Final con- 
clamava os trabalhadores da saúde mental a realizar, com vigor e decisão, a radical transformação das instituiçóes sob inspiração do ambiente pujante da redemocratizaçáo do país, da luta pela cidadania e igualdade de direitos para os pacientes mentais (Brasil, 1988).

Nesse contexto, o tema da criança e do adolescente foi tratado de forma tangencial, incluído apenas no eixo da reforma legislativa, com propostas pouco esclarecedoras e, algumas vezes, contraditórias, como a da afirmação sobre a necessidade de limitação da internação psiquiátrica de crianças (existente de fato em poucas capitais brasileiras) atrelada à defesa da "garantia de educaçáo formal ou especializada, e direito ao espaço lúdico, para os menores internados em instituições psiquiátricas" (Brasil, 1988, p. 3), sem qualquer questionamento sobre esse procedimento. A crítica à "deformação conceitual que [considerava] menores sem lar e meninos de rua como futuros delinquentes e psicopatas" (Brasil, 1988, p. 4), também presente nos debates, não foi acompanhada de propostas para a superação do problema, tornando a crítica esvaziada e sem consequências. A despeito das fragilidades e contradiçóes, essa Conferência teve o mérito de tematizar o problema da criança e adolescente e indicar um certo alinhamento com a crítica ao caráter reducionista e discricionário da categoria "menor" - pauta prioritária do movimento em defesa dos direitos das crianças e adolescentes naquele momento.

A II CNSM, de 1992, de ampla participação nacional e com a presença inédita de usuários e familiares como delegados, foi surpreendente em relação à total ausência de tematização sobre a SMCA. Não há estudos que analisem esse fato e tampouco claras evidências sobre ele. $\mathrm{O}$ caráter surpreendente se acentua quando considerado o contexto daquele momento. Dois anos antes, em 1990, o Brasil assinara a Declaração de Caracas (OPAS, 1990), assumindo o compromisso de reestruturar integralmente a atenção psiquiátrica no país, com a substituição do modelo asilar pelo comunitário, o que determinava, dentre outras coisas, a necessidade de ser aberto um amplo debate com a sociedade e grupos de defesa de direitos com vistas à legitimação do novo modelo (Alves, 2007). A mudança em jogo na assistência ao paciente mental era estrutural, afetaria todos os alicerces da assistência psiquiátrica tradicional e necessitava da legitimação da sociedade para ser iniciada e efetivada. O apoio e compromisso com a questão por parte de movimentos ligados ao tema dos direitos humanos como o de defesa da cidadania para crianças e adolescentes poderiam ser decisivos. Mas não há registro de participação desses grupos nessa Conferência. Por que não foram convocados, ou não se apresentaram ao debate na II CNSM, os militantes da defesa dos direitos das crianças e adolescentes? Por que esse movimento não se mobilizou pela causa da Reforma Psiquiátrica e vice-versa? Por que os militantes da Reforma não incluí- 
ram em sua pauta os problemas de crianças e adolescentes ou não se articularam em prol da defesa dos direitos para eles?

No Relatório Final da II CNSM (Brasil, 1994) há duas singelas e genéricas referências à criança, que não configuram uma tomada de posição política frente à questão da SMCA: uma se refere à inclusão do tema "da saúde da criança nas capacitaçóes do SUS" (Brasil, 1994, p. 20), e a outra à criação "no Ministério da Saúde de uma comissão de proteção dos direitos de cidadania de crianças e adolescentes portadores de sofrimento mental" (Brasil, 1994, p. 23). Esta última, mais próxima da questáo, perde a possibilidade de ser tomada como um posicionamento político vigoroso por constituir proposta única e isolada no conjunto das deliberaçóes registradas em nome da II CNSM.

Em artigo publicado no ano de 2011 sobre o tema da saúde mental e direitos humanos, Delgado (2011) registrou o problema e destacou seu caráter enigmático:

A II Conferência, de 1992, foi extraordinária, a primeira em que os pacientes participaram como delegados, ela formulou as linhas gerais do que o Brasil construiria nos anos seguintes [para a saúde mental]. Porém, seu Relatório Final não faz menção a crianças e adolescentes, apenas uma frase, quase que apenas constatando que esses seres existem. É um fato significativo, pois foi nos anos 90 que mais se discutiam os rumos da política de crianças e adolescentes e os da saúde mental [...] porém, as duas políticas não se encontraram (Delgado, 2011, p. 118, grifos nossos).

Consideramos que a elaboração de possíveis respostas para essa questão deverá enfrentar o complexo debate sobre o não reconhecimento da possibilidade de uma criança portar o enigma da loucura, ou ser um sujeito passível de tormentos mentais. Se essas vicissitudes da condição humana não forem atribuídas a uma criança e não forem tomadas como questóes relevantes ao campo das políticas de cuidado eticamente orientadas, a pauta da cidadania e direitos dos loucos pode não interessar diretamente à pauta da cidadania das crianças; o contrário também sendo verdadeiro. Terá essa questão relação com a surpreendente ausência da SMCA na II CNSM? Certamente deve ser também levado em conta que, na efervescência dos movimentos sociais emancipatórios que marcaram os anos posteriores à Constituição de 1988, o movimento da Reforma Psiquiátrica ia aos poucos construindo uma pauta política própria, no confronto direto com o modelo hospitalocêntrico dominante, cristalizado no manicômio, majoritariamente habitado por adultos, e o tema da saúde mental de crianças e adolescentes não 
ocupava, naquele momento, o centro da agenda de lutas. De qualquer forma, chama a atenção a ausência de um e de outro movimento nas arenas de debate que cada um construiu em nome da renovação democrática do Estado brasileiro.

Ao contrário das duas conferências anteriores, a III CNSM, em 2001, deu ao tema da SMCA lugar de destaque, incluindo-o em sua convocatória e instando municípios e estados a abrir um amplo debate sobre a questão. Antes da etapa nacional, foi realizado um Seminário $\mathrm{Nacional}^{2}$, especificamente voltado para discutir quais seriam os caminhos possíveis para uma política pública de saúde mental da infância e adolescência na realidade brasileira, que reuniu representantes de diferentes estados brasileiros e de diversos setores públicos como saúde, educação, assistência social, justiça, promotoria e saúde mental. Seu caráter intersetorial correspondeu ao que viria a se constituir posteriormente como um dos principais fundamentos da política de SMCA, a intersetorialidade. O Seminário, com a responsabilidade de estabelecer diretrizes ético-políticas capazes de dar sustentabilidade a uma rede de atendimento psicossocial para crianças e adolescentes no sistema de saúde mental do SUS (Brasil, 2001b), elaborou um conjunto de recomendações que foi posteriormente aprovado na íntegra pela plenária final da III CNSM. Destacaram-se como concepções fundamentais: a noção de criança e adolescente como sujeito psíquico e de direitos, a base comunitária da atenção, o desenvolvimento do cuidado através do trabalho em rede e no território e o fundamento intersetorial da política e das açóes de cuidado.

Um elenco resumido das principais deliberaçóes aprovadas na III CNSM indica a direção proposta pela sociedade ao Estado brasileiro para a construção da política de SMCA: a) a SMCA deveria se orientar pelos princípios do ECA, da Lei 10.216 e dos marcos éticos da Reforma Psiquiátrica; b) a criança e o adolescente deveriam ser considerados sujeitos psíquicos e de direitos; c) a política de SMCA deveria integrar a política geral de saúde mental, ter caráter intersetorial e orientar a construção de uma rede de cuidado, de base territorial, sensível às particularidades das crianças e adolescentes e às peculiaridades dos municípios; d) a lógica do CAPS - Centro de Atenção Psicossocial (naquele momento, regulamentado apenas para atendimento de adultos) deveria ser estendida ao cuidado de crianças e adolescentes com problemas mentais; e) a intersetorialidade deveria ser a marca distintiva e estruturante da organização da rede de cuidados em SMCA; f) as açóes de cuidado deveriam se precaver contra a medicalização e institucionalização do sofrimento mental em crianças e adolescentes, que reduziam os problemas advindos da precariedade social a transtornos mentais; g) as práticas de atenção deveriam se opor à finalidade de controle e ajustamento de conduta no trato com a criança e adolescente (Brasil, 2002a). 
Em relação às ações prioritárias a serem desenvolvidas pelo SUS, foi decidido que deveriam ser: a) criados dispositivos de atenção psicossocial para crianças e adolescentes, seguindo a lógica dos CAPS; b) incluídos na pauta da SMCA os problemas da institucionalização de crianças em abrigos da assistência social e filantrópicos, especialmente os destinados aos portadores de deficiência, com vistas à superaçấo definitiva desse processo; c) priorizados na rede de atenção psicossocial os casos de maior gravidade e complexidade; d) realizado um mapeamento nacional sobre os serviços existentes nos diferentes setores públicos ligados à assistência de crianças e adolescentes, incluindo os filantrópicos e do judiciário, de modo a dimensionar os recursos existentes, possibilitar seu melhor aproveitamento nas redes locais e superar os descaminhos da institucionalização; e) criados mecanismos efetivos de participação, com composição intersetorial, incluindo trabalhadores, representantes da sociedade organizada, familiares e usuários para a formulação, acompanhamento e monitoramento da política de SMCA, nos moldes de um fórum interinstitucional a ser implantado nos municípios, estados e na esfera federal do SUS.

As deliberaçóes da III CNSM deixam clara a aproximação com os princípios do ECA e da Reforma Psiquiátrica e ratificam a crença na possibilidade de um Estado como ente de proteção e bem-estar social, indicando a incidência, pela primeira vez na história da saúde mental, da alteração estrutural operada nos elementos da matriz de análise dos problemas da criança que atravessou quase um século da República brasileira.

A $I V C N S M$, de 2010, foi a primeira integralmente intersetorial, desde a convocação até a realização. Os avanços conquistados nos dez anos que se seguiram à Lei 10.216 e à III CNSM e os numerosos desafios que foram revelados com a expansão e territorialização da saúde mental geral, e em grande medida pela SMCA, outorgaram à IV CNSM um valor especial de avaliação de todo esse processo. Em relação à SMCA, foram ratificadas as diretrizes anteriormente propostas na III CNSM e ampliadas significativamente as questóes-chave para o efetivo desenvolvimento da rede de atenção, com especial destaque aos desafios advindos do trabalho intersetorial. A noçâo de rede pública ampliada de atenção se inscreveu como síntese da direçáo a ser conquistada pelo SUS na organização da assistência à SMCA (Brasil, 2011).

Esse breve percurso pelas Conferências Nacionais de Saúde Mental ratifica o argumento de que a III CNSM, de 2001, foi a expressão e síntese de uma história radicalmente nova que começava a ser escrita na SMCA como política pública, sob o marco da cidadania, do direito, da proteção, da atenção psicossocial e, fundamentalmente, sob o reconhecimento de crianças e adolescentes como sujeitos psíquicos. 


\section{Açóes estratégicas para o cuidado psicossocial de crianças e adolescentes: a política de saúde mental em açáo}

Apenas dois meses depois da III CNSM, em fevereiro de 2002, foi publicada a Portaria 336/2002 (Brasil, 2002b) ${ }^{3}$, contendo um capítulo especificamente destinado à criação de Centros de Atenção Psicossocial para crianças e adolescentes, os CAPSi. As orientaçóes contidas nessa Portaria, a primeira na história do SUS com orientaçôes para a SMCA, indicaram a incorporação pelo Ministério da Saúde de algumas das mais importantes aspiraçóes emanadas da III CNSM. Dois anos depois, em 2004, foi criado, também pelo Ministério da Saúde, o Fórum Nacional sobre Saúde Mental de Crianças e Adolescentes (Brasil, 2004, 2005), um mecanismo democrático de participação e deliberação, de composição intersetorial e com representação de usuários e familiares, para formulação e orientação das açôes relacionadas à política de SMCA. Com função de elaborar coletivamente o diagnóstico das situaçôes, estabelecer estratégias, propor diretrizes para a articulação intersetorial, avaliar os resultados e acompanhar a implantação das redes ampliadas de cuidado, o Fórum Nacional expressa e encarna o fundamento político, clínico e intersetorial que constitui a política de SMCA nos novos tempos da história brasileira. Nove reunióes ordinárias foram realizadas desde a criação do Fórum até o presente momento (Brasília, 2013) ${ }^{4}$, tematizando questóes relevantes para o cenário nacional como a institucionalizaçấo de crianças e adolescentes, uso indevido de drogas, o desafio da construção de redes psicossociais em um país marcado por enorme diversidade regional e os impasses para consolidação da intersetorialidade, dentre outros. Orientado pelo princípio do trabalho em colaboração com os setores da educação, assistência social, justiça e direitos, historicamente envolvidos na assistência às crianças e adolescentes, o Fórum se inscreve na agenda da SMCA como um importante instrumento de gestão da política pública. Cada reunião ordinária foi sucedida pela elaboração de documentos oficiais contendo recomendaçóes e orientaçôes aos gestores, equipes e serviços de todo o país com objetivo de dar institucionalidade às transformaçóes necessárias e impulsionar as açóes locais na direção da construçáo de redes sensíveis ao mandato psicossocial.

A criação dos CAPSi e o direcionamento intersetorial constituem açôes-chave para alavancar a montagem da rede pública ampliada de atençáo em SMCA no país, com capacidade de acolher as diferentes ordens de problemas implicados na SMCA e ampliar o acesso, tendo como base o fundamento ético do cuidado em liberdade.

Os CAPSi constituem a primeira açáo concreta oriunda da nova posiçáo do Estado brasileiro frente às questóes da SMCA. Compostos por equipes mul- 
tiprofissionais, fundamentados na lógica da atenção diária, da intensividade do cuidado, do trabalho em rede e baseados na comunidade, visam à ampliação dos laços sociais possíveis a cada um dos seus usuários e familiares. Inauguram a resposta oficial do SUS à necessidade de cuidado para crianças e adolescentes com problemas mentais que, até aquele momento, não encontravam na atenção psicossocial possibilidade real de atendimento. Orientados prioritariamente para o atendimento dos casos de maior gravidade e complexidade, devem também exercer a função de ordenadores da demanda em SMCA no seu território de referência, sintetizando, em um único dispositivo, o mandato terapêutico e o gestor na atenção psicossocial de crianças e jovens. Foram instituídos como dispositivos estratégicos na construção da rede de atenção psicossocial e não como serviços assistenciais especializados, em grande medida pelo histórico de ausência de conhecimento clínico, epidemiológico e sobre a organização de serviços para SMCA que antecedeu a proposição da política de SMCA no país. Além de contribuir para ampliação desses conhecimentos, o exercício do duplo mandato - terapêutico e gestor - representa a principal inovação na oferta de CAPSi pelo SUS por incorporar em um único dispositivo açóes terapêuticas e gestoras das demandas territoriais, implicando de modo indissociável o território, a intersetorialidade e a rede como montagens articuladas e colaborativas para realizar o desafio de expandir o acesso e qualificar o cuidado. Para Harper (2012, p. 7), o projeto brasileiro do CAPSi constitui "um programa ambicioso", principalmente por situar no nível comunitário da atenção a complexidade do tratamento do problema mental, visar parcerias para a ampliação dos laços sociais possíveis a cada um dos seus usuários e por convocar articulaçôes entre serviços e setores públicos, inaugurando, pela via da responsabilidade política, a tentativa de superar a fragmentação da atenção em SMCA ainda presente no Brasil.

\section{Alguns desafios}

Passados mais de dez anos, esse ambicioso projeto tem indicado potência no desenvolvimento das açóes de cuidado nas localidades onde foi implantado, esforçando-se para responder com efetividade às demandas complexas da saúde mental de crianças e jovens, inscrevendo a família como parceira do cuidado e desenvolvendo práticas inovadoras baseadas na interdisciplinaridade e na articulação dos recursos comunitários e intersetoriais (UFRJ, 2013). No entanto, o percurso já realizado vem também expondo a existência de problemas estruturais que vão requerer açóes e investimentos consistentes para que sejam efetivamen- 
te superados e não obstaculizem a consolidação da política de SMCA no país. Ainda é insuficiente o número de CAPSi implantados (apenas 183 serviços no ano de 2013), contrastando com a expansão e distribuição regional alcançada pelos CAPS para adultos no mesmo período (cerca de 2000, presentes em todas as regiões do país); são escassas as estratégias de formação para os trabalhadores da rede, comprometendo o pleno exercício do mandato clínico e gestor inaugurado pelo CAPSi que, por seu caráter inovador, exige acompanhamento e açóes de formação permanentes; há enorme fragilidade nos vínculos de trabalho dos profissionais, com forte tendência à terceirização das contrataçóes, baixos salários e ausência de garantias para permanência no sistema de saúde; ainda é incipiente o entendimento de gestores da área da saúde e saúde mental sobre as atribuições do CAPSi no território e na montagem de redes locais, diluindo sua especificidade e contribuindo para sua pequena expansão no território nacional; há falta de implantação do dispositivo da supervisão clínico-institucional na grande maioria dos CAPSi, que, se existente, poderia qualificar e potencializar o trabalho das equipes (UFRJ, 2013). Somados a esses desafios, há indicativos de baixa institucionalidade das redes de atenção em certas localidades do país, com poucos serviços em funcionamento ou atuando de forma desarticulada, e, ainda, enorme carência de estratégias de avaliação e monitoramento sintonizadas com o mandato psicossocial que possam auxiliar a sistematização do conhecimento produzido, indicar pontos a serem melhor desenvolvidos e contribuir para efetiva inscrição da atenção psicossocial como modo de cuidado na SMCA.

No que diz respeito à estratégia de desenvolvimento e gestão da política de SMCA representada pelo Fórum Nacional, este, apesar de ter se revelado um importante dispositivo público, vem encontrando um esvaziamento de sua função deliberativa e um aparente desinvestimento por parte da gestão do SUS. A realização de suas reunióes ordinárias foi marcada por um significativo hiato nos últimos anos, sem convocatória entre 2009 e 2012 (a última reunião ocorreu em novembro de 2012), comprometendo a regularidade da ação participativa e, consequentemente, a potência da ação política. Do mesmo modo, as recomendaçóes e orientaçóes oficiais emanadas do Fórum, que constituem a base das mudanças a serem implantadas nos territórios, encontraram enormes dificuldades de disseminação e difusão por parte das esferas de gestão da saúde mental e, portanto, de incidência nas realidades locais, fragilizando o processo transformador exigido pela inscrição da atenção psicossocial como modalidade de cuidado às crianças e adolescentes. A superação desse impasse requer o real comprometimento do SUS com a questão da SMCA e o estabelecimento de mecanismos mais consistentes de transmissão e acompanhamento das açóes locais para que o processo 
de consolidação da política não encontre solução de continuidade. São também escassas as experiências municipais ou estaduais de constituição de Fóruns locais, que, se implementados, poderiam contribuir significativamente para o avanço da inovação representada pela atenção psicossocial no país a partir de mecanismos participativos e deliberativos, envolvendo setores públicos, usuários, familiares e a sociedade civil organizada.

Conclui-se, dessa forma, que as duas ações prioritárias propostas pela política pública para iniciar o processo de construção de redes ampliadas de atenção em SMCA no país são potentes e promissoras, afinam-se à necessidade de superação da história anterior, marcada pela desassistência e ausência de projetos públicos, mas não estão consolidadas, dependendo fortemente de investimentos substanciais pelas esferas de gestão do SUS para que possam se inscrever na realidade brasileira como marcos de um novo tempo e de um novo modo de cuidar e tratar de crianças e adolescentes em sofrimento mental.

\section{Referências}

Almeida, N. C. \& Delgado, P. G. (2000). De volta à cidadania. Politicas públicas para crianças $e$ adolescentes. Rio de Janeiro: Ed. IFB/Funlar.

Alves, D. S. (2007). Encontro Nacional: 20 anos de luta por uma sociedade sem manicômios. Bauru. (DVD).

Arantes, E. M. M. (1995). Rostos de crianças no Brasil. In F. Pilotti \& I. Rizzini (Eds.). A arte de governar crianças. A história das politicas sociais, da legislação e da assistência à infância no Brasil (p. 171-220). Rio de Janeiro: Ed. Amais.

Arendt, H. (2002). A dignidade da política. In A. Abranches (Ed.). Rio de Janeiro: Ed. Relume Dumará. (Original publicado em 1993).

Brasil [Ministério da Saúde]. (1988). Relatório Final da I Conferência Nacional de Saúde Mental. Brasília, DF.

Brasil (1990). Lei no 8.069, de 13 de julho de 1990. Dispóe sobre o Estatuto da Criança e do Adolescente e dá outras providências. Brasília, DF: Diário Oficial da União.

Brasil [Ministério da Saúde]. (1994). Relatório Final da II Conferência Nacional de Saúde Mental. Brasília, DF.

Brasil (2001a). Lei no 10.216, de 6 de abril de 2001. Dispóe sobre a proteção e os direitos das pessoas portadoras de transtornos mentais e redireciona o modelo assistencial em saúde mental. Brasília, DF: Diário Oficial da União.

Brasil [Ministério da Saúde]. (2001b). Seminário Nacional Política de Saúde Mental para Infância e Adolescência (Relatório Final). Brasília, DF. 
Brasil [Ministério da Saúde]. (2002a). Relatório Final da III Conferência Nacional de Saúde Mental. Brasília, DF.

Brasil [Ministério da Saúde]. (2002b). Portaria 336, de 19 de fevereiro de 2002. Dispóe sobre as normas e diretrizes para organização dos CAPS. Brasília, DF: Diário Oficial da União.

Brasil [Ministério da Saúde]. (2004). Portaria 1608, de 3 de agosto de 2004. Constitui o Fórum Nacional sobre Saúde Mental de Crianças e Adolescentes. Brasília, DF: Diário Oficial da União.

Brasil [Ministério da Saúde]. (2005). Caminhos para uma Política de Saúde Mental Infanto-Juvenil. Brasília, DF.

Brasil [Ministério da Saúde]. (2011). Relatório Final da IV Conferência Nacional de Saúde Mental. Brasília, DF.

Brasil [Ministério da Saúde]. (2013). Fórum Nacional Infanto-Juvenil. Recomendações. Versão Preliminar. Brasília, DF.

Cirino, O. (2001). Psicanálise e psiquiatria com crianças: desenvolvimento ou estrutura. Belo Horizonte: Ed. Autêntica.

Costa, J. F. (1976). Ordem médica e norma familiar. Rio de Janeiro: Ed. Graal.

Couto, M. C. V. (2004). Por uma Política Pública de Saúde Mental para crianças e Adolescentes. In T. Ferreira (Ed.), A criança e a saúde mental: enlaces entre a clinica e a politica (p. 61-74). Belo Horizonte: Ed. Autêntica.

Couto, M. C. V., Duarte, C. S., \& Delgado, P. G. G. (2008). A Saúde Mental Infantil na Saúde Pública Brasileira: situação atual e desafios. Revista Brasileira de Psiquiatria, 30(4), 390-398.

Delgado, P. G. G. (2011). Saúde Mental e Direitos Humanos: 10 anos da Lei 10.216/2001. Arquivos Brasileiros de Psicologia, 63(2), 114-121.

Engel, M. G. (1995). A loucura na cidade do Rio de Janeiro: ideias e vivências (1830-1930). (Tese de Doutorado. Curso de Pós-Graduação em História, Universidade Estadual de Campinas, Campinas, SP).

Ferreira, T. (1999). A escrita da clínica. Psicanálise com crianças. Belo Horizonte: Ed. Autêntica. Harper. G. (2012). Child and adolescent mental health policy. In J. M. Rey (Ed.), IACAPAP e-textbook or Child and Adolescent Mental Health. Geneva: IACAPAP.

Lobo, L. F. (1997). Os infames da história: a instituição das deficiências no Brasil. (Tese de Doutorado. Curso de Pós-Graduação em Psicologia, Pontifícia Universidade Católica, Rio de Janeiro, RJ).

Mendes, E. G. (1998). Infância e cidadania na América Latina. São Paulo: Ed. Hucitec.

Müller, T. M. (1998). A primeira escola especial para crianças anormais do Distrito Federal: o Pavilhão Bourneville do Hospício Nacional de Alienados. (Dissertação de Mestrado. Curso de Pós-Graduação em Educaçáo, Universidade do Estado do Rio de Janeiro, Rio de Janeiro, RJ).

Organização das Naçóes Unidas/ONU (1989). Convenção sobre os Direitos da Criança.

Psic. Clin., Rio de Janeiro, vol. 27, N.I, P. I7 - 40, 2015 
Organização Panamericana de Saúde/OPAS (1990). Declaração de Caracas. Conferência Regional para Reestruturação da Atenção Psiquiátrica na América Latina no Contexto dos Sistemas Locais de Saúde.

Pilotti, F. (1995). Crise e perspectivas da assistência à infância na América Latina. In F. Pilotti, \& I. Rizzini (Eds.). A arte de governar crianças. A história das politicas sociais, da legislação e da assistência à infância no Brasil (p. 11-45). Rio de Janeiro: Ed. Amais.

Priore, M. D. (1995). História da criança no Brasil. São Paulo: Ed. Contexto.

Rizzini, I. (1993). Assistência à infância no Brasil. Uma análise de sua construção. Rio de Janeiro: Ed. Universitária Santa Úrsula.

Rizzini, I. (1997). O século perdido. Raizes históricas das políticas públicas para infância no Brasil. Rio de Janeiro: Ed. Amais.

Rizzini, I. (2010). Do confinamento ao acolhimento. Institucionalização de crianças e adolescentes com deficiência: desafios e caminhos. Rio de Janeiro: CIESPI-PUC/RJ.

Rizzini, I., \& Rizzini, I. (2004). A institucionalização de crianças no Brasil. Percurso histórico e desafios do presente. São Paulo: Ed. Loyola.

Rua, M. G. (1998). As políticas públicas e a juventude dos anos 90. In Jovens acontecendo na trilha das politicas públicas (p. 731-752). Brasília: CNPD.

Schechtman, A. (1981). Psiquiatria preventiva: infância e eufrenia. (Dissertação de Mestrado. Curso de Pós-Graduação em Medicina Social, Universidade do Estado do Rio de Janeiro, Rio de Janeiro, RJ).

Silva, R. P. (2008). Medicina, educação e psiquiatria para infância: o Pavilhão-Escola Bourneville no início do século XX. (Dissertação de Mestrado. Curso de Pós-Graduação em História das Ciências, Casa de Oswaldo Cruz, Fiocruz, Rio de Janeiro, RJ).

Universidade Federal do Rio de Janeiro/UFRJ/IPUB/NUPPSAM (2013). Anais do I Congresso Brasileiro de Centros de Atenção Psicossocial - I CONCAPSi. Rio de Janeiro: UFRJ/UERJ. Recuperado em 21 de janeiro de 2014, de <www.nuppsam.org>.

Venâncio, R. P. (1999). Famílias abandonadas: a Assistência à criança de camadas populares no Rio de Janeiro e em Salvador - séculos XVIII e XIX. Campinas: Papirus.

Vogel, A. (1995). Do Estado ao Estatuto. Propostas e vicissitudes da política de atendimento à infância e adolescência no Brasil contemporâneo. In F. Pilotti, \& I. Rizzini (Eds.). A arte de governar crianças. A história das políticas sociais, da legislação e da assistência à infância no Brasil (p. 299-346). Rio de Janeiro: Ed. Amais.

\section{Notas}

${ }^{1}$ Os períodos históricos da Colônia e Monarquia não serão considerados aqui, uma vez que não se pode com precisão subsumir ao conceito de "política pública", objeto deste artigo, as 
ações e iniciativas desses períodos relacionadas à infância pobre as quais, quando existentes, foram eminentemente filantrópicas e majoritariamente providas pela Igreja Católica. De todo modo, até a ruptura com o paradigma menorista, a identificação da infância com a pobreza e sua institucionalização como direçóes da ação do Estado são semelhantes na Monarquia e na República Velha (o Código Civil republicano de 1916 não contém inovaçôes relevantes sobre o tema, quase inexistente como questão à época, de eventual estatuto civil da infância, se comparado às leis civis da Monarquia). Além do que não existia sequer o "menor", praticamente ausente da Consolidação das Leis Civis Brasileiras, de Teixeira de Freitas, vigente na Monarquia, um regime escravocrata e, portanto, incompatível com códigos de direitos civis (para o tema, consultar Rizzini \& Rizzini, 2004; e Venâncio, 1999).

${ }^{2}$ Seminário Nacional de Politica de Saúde Mental para Infância e Adolescência, realizado nos dias 3 e 4 de dezembro de 2001, no Instituto de Psiquiatria da Universidade Federal do Rio de Janeiro, como evento prévio à etapa nacional da III Conferência Nacional de Saúde Mental. Reuniu 74 profissionais dos campos da saúde mental, educação, assistência social, justiça e direitos, oriundos de diversos estados da federação, com a responsabilidade de estabelecer diretrizes ético-políticas para balizar a construção da rede de atendimento psicossocial para crianças e adolescentes no sistema público de saúde mental brasileiro.

${ }^{3}$ A Portaria 336/2002 estabelece cinco tipologias de CAPS, de acordo com a população-alvo e o porte populacional das cidades: CAPS I, II, III, i, AD. Além disso, cria uma tipologia para a complexidade das situaçóes clínicas atendidas, com as categorias: atendimento "intensivo, semi-intensivo e não-intensivo". Os CAPSi passaram a existir como dispositivos do SUS a partir dessa Portaria.

${ }^{4}$ O Fórum Nacional de Saúde Mental Infanto-Juvenil, coordenado pelo Ministério da Saúde, realizou reunióes em 2003 (preparatória), 2004 (uma para implantaçáo oficial e outra com o tema da institucionalização de crianças e adolescentes), 2005 (com tema da articulaçáo do campo da saúde e do direito na atenção à infância e adolescência), 2006 (uma com o tema das crianças e adolescentes em situação de risco e outra com o do sofrimento psíquico na infância e adolescência e a necessidade do cuidado em rede), 2007 (com o tema da intersetorialidade), 2009 (com o tema do uso indevido de álcool e drogas) e 2012 (com o tema do desafio na implantação da Rede de Atençâo Psicossocial, RAPS). Para maior conhecimento das recomendaçóes emanadas dos Fóruns, ver: Brasil, MS, 2013.

Recebido em 06 de fevereiro de 2014 Aceito para publicação em 18 de maio de 2014

DOI: $10.1590 / 0103-56652015000100002$ 